\title{
PENGGUNAAN EKSTRAK TEMBAKAU SEBAGAI INHIBITRO PADA BETON BERTULANG MENGGUNAKAN PASIR LAUT DAN AIR LAUT
}

\author{
Mufti Amir Sultan ${ }^{1)}$, Muh. Yunus Hi. Abbas ${ }^{2)}$, Abdul Gaus ${ }^{3)}$, Khusna Arif \\ Rakhman $^{4}$ Nurtalia Barmawi ${ }^{5)}$ \\ ${ }^{1,3)}$ Program Studi Teknik Sipil, Universitas Khairun \\ ${ }^{2)}$ Program Studi Teknik Elektro, Universitas Khairun \\ ${ }^{4)}$ Program Studi Pendidikan Kimia, Universitas Khairun \\ Coresponding email: muftiasltn@unkhair.ac.id ${ }^{1}$ \\ DOI: http://dx.doi.org/10.29103/tj.v10i1.264
}

(Received: December 2019 / Revised: February 2020 / Accepted: March 2020)

\begin{abstract}
Abstrak
Korosi dapat didefenisikan secara umum sebagai pengrusakan bahan oleh lingkungannya. Struktur beton bertulang akan mengalami kerusakan akibat serangan korosi, apabila tidak ditangani akan membutuhkan biaya yang relative mahal untuk memperbaikinya. Korosi pada baja tulangan harus ditangani secara khusus, oleh sebab itu diperlukan solusi untuk mengatasi masalah ini. Pencegahan korosi bergantung pada jenis korosi yang terjadi pada material terkorosi. Salah satu metode yang terus di kaji saat ini adalah pencegahan korosi dengan menggunakan inhibitor. Dalam penelitian ini, inhibitor yang digunakan adalah inhibitor ekstrak daun tembakau dengan variasi dan konsentrasi yang telah ditentukan yakni $0 \%, 4 \%$ dan $8 \%$. Metode yang digunakan untuk menganalisis laju korosi yang terjadi yaitu metode Weight Loss (kehilangan berat). Pengujian dilakukan dengan cara memberikan aliran listrik terhadap benda uji dengan menggunakan voltase sebesar 5V. Pengaliran dilakukan secara bertahap dengan interval tertentu, sehingga diperoleh efeisiensi inhibisi dalam satuan persen. Hasil penelitian menunjukkan pengaruh penambahan inhibitor ekstrak tembakau dengan metode weight loss pada konsentrasi $4 \%$ dan $8 \%$ mampu menurunkan rapat arus anodik dan katodik yang mengakibatkan laju korosi pada baja tulangan, peningkatan konsentrasi inhibitor ekstrak tembakau pada masing-masing variasi campuran beton memiliki efesiensi inhibitor yang baik yakni $64,44 \%$ dengan air pencampur air tawar dan $20 \%$ untuk air laut pada setiap konsentrasi inhibitor $8 \%$ ekstrak tembakau.
\end{abstract}

Kata Kunci: Korosi, tembakau, air laut, pasir laut, inhibitor

\begin{abstract}
Corrosion can be generally defined as the destruction of material by the environment. Reinforced concrete structures will suffer damage due to corrosion attacks, if left untreated will require a relatively expensive cost to repair them. Corrosion of reinforcing steel must be handled specifically. Therefore we need a solution to overcome this problem. Corrosion prevention depends on the type of corrosion that occurs in corroded material. One method that continues to be studied today is the prevention of corrosion by using inhibitors. In this study, the inhibitors used were tobacco leaf extract inhibitors with a predetermined variation and concentration of $0 \%, 4 \%$ and $8 \%$. The method used to analyze the corrosion rate that occurs is the Weight Loss method. The test is carried out by giving an electric current to the test object using a voltage of $5 \mathrm{~V}$. Draining is done in stages with a certain interval, so that the inhibition efficiency is obtained in percent units. The results showed the effect of
\end{abstract}

Penggunaan Ekstrak Tembakau Sebagai Inhibitro Pada Beton Bertulang Menggunakan Pasir Laut Dan Air Laut - Mufti Amir Sultan, Muh. Yunus Hi. Abbas, Abdul Gaus, Khusna Arif Rakhman, Nurtalia Barmawi 
adding tobacco extract inhibitors by weight loss method at concentrations of $4 \%$ and $8 \%$ were able to reduce the density of anodic and cathodic currents which resulted in corrosion rates in reinforcing steel. Increasing the concentration of tobacco extract inhibitors in each variation of the concrete mixture had an efficient inhibitor efficiency. both $64.44 \%$ with freshwater mixing water and $20 \%$ for sea water at each concentration of $8 \%$ inhibitor of tobacco extract.

Keywords: Corrosion, tobacco, sea water, sea sand, inhibitors

\section{Latar Belakang}

Sebagai kota kepulauan, wilayah Ternate didominasi oleh laut, maka iklimnya dipengaruhi oleh iklim laut, yang tentunya akan sangat berpengaruh bagi kualitas infrastruktur yang ada di daerah ini. Infrastruktur yang ada umumnya terbuat dari beton bertulang yang tentunya akan sangat rentan terjadi korosi khususnya pada tulangan. Atas dasar ini maka pentingnya pengendalian korosi pada infrastruktur sebagai upaya pencegahan korosi dan mempertahankan masa layan dari struktur tersebut.

Korosi dapat didefinsikan secara umum sebagai pengrusakan bahan oleh lingkungannya, (Bahri, 2007) menyatakan bahwa pengrusakan yang dimaksud adalah kerusakan atau degradasi logam akibat reaksi redoks antara suatu logam dengan berbagai zat di lingkungannya yang menghasilkan senyawa-senyawa yang tidak dikehendaki. Dalam bahasa sehari-hari, korosi disebut perkaratan

Beton bertulang (reinforced concrete) merupakan suatu bahan konstruksi yang biasa digunakan untuk membuat bangunan. Beton bertulang ini merupakan gabungan dari beton dengan baja yang berfungsi sebagai tulangan penahan gaya tarik. Tulangan ini didesain khusus untuk memperkuat beton pada suatu konstruksi bangunan. Baja tulangan yang digunakan sebagai bagian elemen yang menahan gaya tarik cenderung akan mengalami korosi apabila kontak dengan udara dan lingkungan laut.

Pencegahan korosi bergantung pada jenis atau tipe korosi yang terjadi pada material terkorosi. Ada beberapa cara pencegahan korosi. Salah satu metode yang terus dikaji saat ini adalah pencegahan korosi dengan menggunakan inhibitor alami. Inhibitor umumnya berasal dari senyawa anorganik atau organik. Inhibitor organik alami bekerja dengan membentuk senyawa kompleks yang mengendap (adsorpsi) pada permukaan logam sebagai lapisan pelindung yang bersifat hidrofobik yang dapat menghambat reaksi logam tersebut dengan lingkungannya. Reaksi tersebut dapat berupa reaksi anodik dan katodik ataupun keduanya. Inhibitor organik diklasifikasin menjadi inhibitor organik sintesis yang berasal dari bahan bakar fosil dan inhibitor organik alami yang terbuat dari ekstrak tanaman.

Inhibitor organik alami adalah inhibitor yang dibuat dengan mengekstraksi tanaman untuk pencegahan korosi. Inhibitor ini telah menjadi prioritas bagi para peneliti karena diusulkan untuk menggantikan aplikasi inhibitor bahan kimia yang merupakan zat berbahaya bagi lingkungan. Penelitian tentang inhibitor organik alami telah semakin meningkat karena inhibitor organik alami aman, dan tidak merusak lingkungan. Inhibitor organik alami juga dapat ditemukan atau diproduksi dengan mudah. Ada banyak penelitian telah dilakukan untuk menyelidiki sumber daya alam ini selama bertahun-tahun, antara lain: Penelitian dengan menggunakan ekstrak daun teh sebagai inhibitor, menyatakan bahwa 
ekstrak daun teh dapat menghambat korosi (Ludiana and Handani, 2012), (Sari, Handani and Yetri, 2013), (Yetri, Sari and Handani, 2016). Penelitian dengan menggunakan ekstrak kulit buah manggis (inhibitor) dengan variasi konsentrasi dimulai $2 \%$ dengan kenaikan tiap $2 \%$ sampai mencapai $10 \%$. Inhibitor ini dimasukkan ke dalam medium korosif dengan larutan $\mathrm{NaCl}$, Hasl penelitian ini menunjukkan bahwa ekstrak kulit buah manggis dapat menghambat laju korosi (Turnip, Handani and Mulyadi, 2015).

Penelitian dengan memanfaatkan tanin sebagai senyawa organik yang dapat digunakan sebagai inhibitor, di mana tannin diperoleh dengan mengestraksi daun jambu biji. Dalam penelitian ini yang digunakan sebagai parameter adalah konsentrasi ekstrak, media pengkorosi berupa larutan asam dan garam serta lama perendaman. Dari penelitian ini diperoleh persen proteksi 56,29\% dengan lama perendaman 4 hari pada kadar inhibitor 1000 ppm (Ali, Saputri and Nugroho, 2014). Penelitian untuk mengendalikan laju korosi pada baja dengan memanfaatkan ekstrak daun gambir dengan sampel yang direndam dalam medium korosif tanpa ekstrak daun gambir dibandingkan dengan sampel dalam medium korosif yang telah ditambahkan eskstrak daun gambir pada konsentrasi $0,5 \%$ sampai 2\%. Sampel direndam dengan berbagai variasi waktu sampai 15 hari. Dari hasil Analisa SEM dapat disimpulkan bahwa ekstrak daun gambir dapat menghambat laju korosi pada baja (Murti, Handani and Yetri, 2016).

Penggunaan ekstrak daun salam sebagai penghambat korosi pada baja plat hitam digunakan dalam penelitian ini, pertimbangan penggunaan daun salam sebagai inhibitor dikarenakan mengandung senyawa flavonoid dan tannin. Medium korosif yang digunakan adalah $\mathrm{NaCl} 3 \%$, dari hasil penelitian disimpulkan bahwa ekstrak daun salam dapat menghambat laju korosi (Yufita and Fitriana, 2018). Penggunaan bubuk azadirachta indica (neem) dan ekstrak lidah buaya sebagai inhibitor korosi untuk baja dalam beton. Beton ditanam dalam larutan dengan salinitas sekitar 3,5\%. Beton dengan inhibitor ekstrak lidah buaya telah mengurangi laju korosi baja pada beton dari $0,3 \mathrm{~mm} / \mathrm{y}$ menjadi $0,22 \mathrm{~mm} / \mathrm{y}$. Inhibitor ekstrak lidah buaya menunjukkan bahwa laju korosi berkurang menjadi $0,27 \mathrm{~mm} / \mathrm{y}$. Hasil inhibitor menunjukkan bahwa azadirachta indica (neem) memiliki efisiensi korosi yang lebih baik dibandingkan dengan inhibitor lidah buaya (Lisha, Rajalingam and George, 2017). Penambahan inhibitor alam seperti duan gambir, getah pinus, ekstrak kopi dan ekstrak tembakau dapat mengurangi laju korosi besi dalam larutan air laut. Inhibitor alam yang dapat mengurangi laju korosi paling baik adalah getah pinus (Haryono, Sugiarto and Farid, 2010). Inhibitor organik alami dapat membentuk lapisan film atau hidrofobik pada permukaan logam atau paduan logam yang dapat melindungi logam atau paduan logam tersebut dari serangan korosi dalam lingkungan yang korosif. Keefektifan inhibitor organik alami bergantung pada struktur molekul, susunan kimia, dan afinitasnya terhadap permukaan logam atau paduan logam (Yatiman, 2009).

Penelitian dengan menggunakan ekstrak limbah kulit jeruk, dengan mengekstraksi kulit jeruk kering menggunakan ekstrak metanol pada waktu perendaman 6 jam dalam metanol pada tekanan $(60$ mbar $)$ dan $40^{\circ} \mathrm{C}$. Dari data eksperimen menggunakan pengukuran polarisasi elektrokimia dan pengujian kehilangan berat. Menunjukkan bahwa laju korosi tulangan menurun menjadi 0,02 $\mathrm{mm} /$ tahun pada konsentrasi 3\% inhibitor (Abbas, Fazakas and Torok, 2018). Pemanfaatan limbah puntung rokok digunakan sebagai inhibitor untuk mengetahu 
laju korosi pada paku besi, di mana konsentrasi inhibitor yang digunakan sebesar 200 ppm sampai 1000 ppm dan waktu perendaman 7 hari. Hasil penelitian menyimpulkan bahwa semakin tinggi konsentrasi limbah puntung rokok maka laju korosi semakin kecil (Andeka, Suharto and Haji, 2015). Penggunaan ekstrak tembakau, puntung rokok dan kopi sebagai inhibitor, dari hasil penelitian menunjukkan bahwa ekstrak daun tembakau lebih baik dibandingkan dengan puntung rokok dan ekstrak kopi (Istiqlaliyah and Candrama, 2018). Pemanfaatan abu dari hasil pembakaran sekam padi sebagai inhibitor alami dapat menghambat korosi pada tulangan baja (Usman, Sultan and Abbas, 2019).

Inhibitor organik alami terbukti efektif dari perspektif ekologis dan lingkungan dan dapat memainkan peran utama dibandingkan inhibitor sintetis. Di masa mendatang inhibitor organik alami akan lebih diminati mengingat produk tanaman muncul sebagai penghambat korosi yang efektif karena ramah lingkungan, ketersediaannya yang mudah, sifatnya yang murah dan tidak beracun (Khan et al., 2015). Penggunaan inhibitor alami akan terus digunakan untuk pencegahan korosi di masa depan dengan modifikasi lebih lanjut. Perbaikan masa depan harus menggabungkan jenis inhibitor dengan sifat adsorpsi yang sangat baik dan mekanisme anodik atau katodik untuk mencapai inhibitor alam dengan kinerja yang paling baik (Asmara et al., 2018).

\section{Metode Penelitian}

Ekstrak tembakau yang digunakan diperoleh dengan metode maserasi, metode pembuatan ekstrak tembakau seperti ditunjukkan pada Gambar 1.
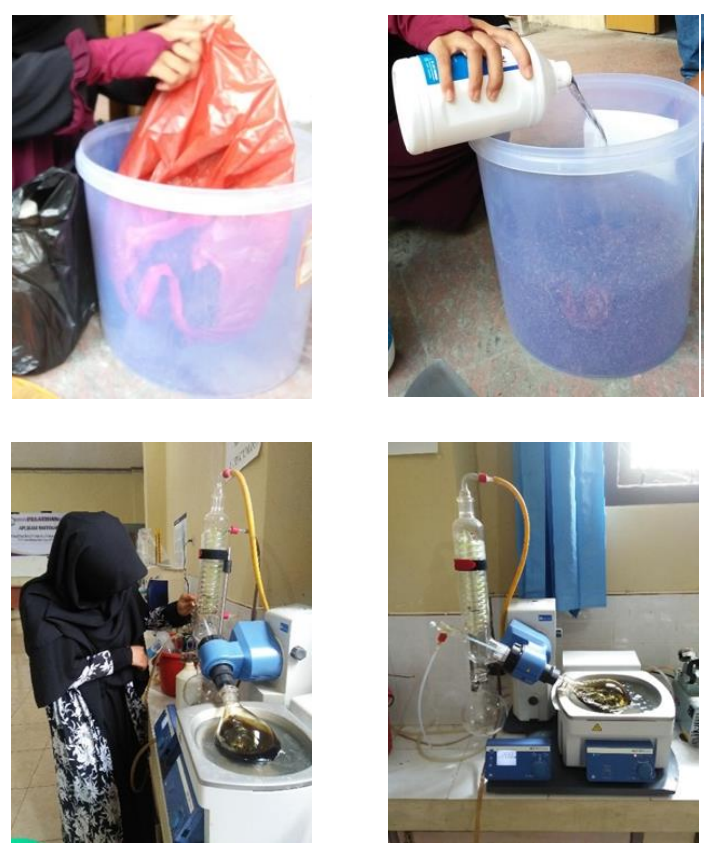

Gambar 1 Pembuatan Ekstrak Daun Tembakau dengan Metode Maserasi

Benda uji yang digunakan dalam penelitian ini berupa silinder beton bertulang berpenampang: tinggi $300 \mathrm{~mm}$, lebar 101,6 mm, dan berdiameter 10 
mm seperti pada Gambar 2. Total benda uji yang digunakan sebanyak 36 benda uji.

Sampel beton menggunakan semen PC (Portland cement), agregat halus dari Quarry Loto (pasir pantai) dan agregat kasar dari Quarry Togafo, air yang digunakan sebagai pencampur berasal dari air laut dengan salinitas 3,5\% dan tulangan besi beton $\phi 10$ panjang $300 \mathrm{~mm}$. Tahapan pembuatan adukan beton adalah dengan melakukan penimbangan bahan-bahan, seperti semen, pasir, kerikil, ekstrak tembakau dan besi sesuai dengan kebutuhan rencana campuran adukan beton. Kemudian memasukkan semen, pasir, krikil, air dan ekstrak tembakau kedalam bak pengecoran dan kemudian dicampur secara manual dengan menggunakan sendok semen. Setelah semua bahan tercampur kemudian dilakukan pengujian slump test untuk mengatahui keenceran atau kekentalan campuran beton. Selanjutnya mempersiapkan cetakan-cetakan yang akan dipakai untuk mencetak benda uji dengan terlebih dahulu diolesi oli. Memasukan adukan beton kedalam cetakan dengan memakai cetok, kemudian letakan baja tulangan ditengah campuran. Adukan yang telah dicetak ditempatkan pada tempat yang terlindungi dari sinar matahari dan hujan serta didiamkan \pm 24 jam. Kemudian benda uji dikeluarkan dari cetakan dan direndam dalam larutan $\mathrm{NaCl}$ selama 28 hari.

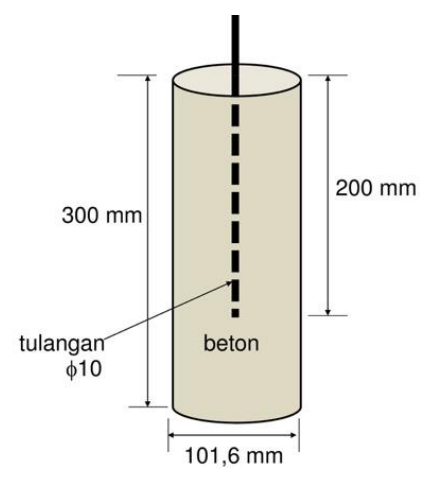

Gambar 2 Ukuran benda uji

Setup pengujian seperti pada Gambar 3, pengujian dilakukan dengan cara memberikan aliran listrik terhadap benda uji dengan menggunakan voltase sebesar 5V. Pengaliran dilakukan secara bertahap dengan interval tertentu, sehingga diperoleh efeisiensi inhibisi dalam satuan persen.

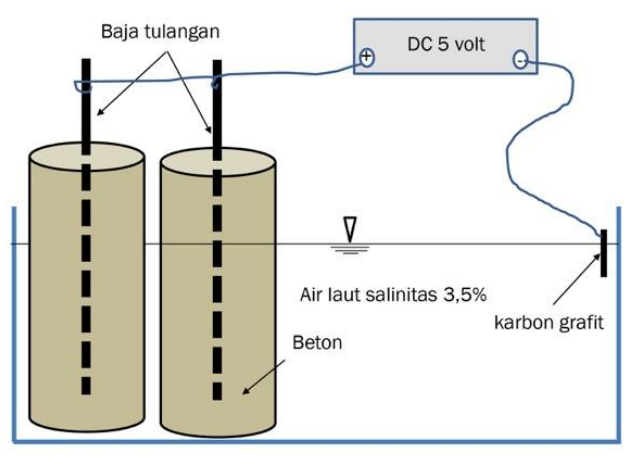

Gambar 3 Mekanisme Pengujian Korosi dengan Mengaliri Arus Listrik 
Analisis data digunakan dengan Metode weight loss atau kehilangan berat untuk mengetahui laju korosi. Prinsip dari metode ini adalah dengan menghitung banyaknya material yang hilang atau kehilangan berat setelah dilakukan pengujian rendaman dengan dialiri listrik. Dengan mengambil beberapa data seperti masa logam awal sebelum mengalami korosi, masa logam akhir setelah mengalami korosi, luas permukaan yang terendam, waktu perendaman dan massa jenis logam yang di uji setelah itu data-data tersebut dimasukan kedalam persamaan berikut:

$$
\text { Corrosion Rate }=\frac{K-W}{D \times A x T}
$$

di mana $\mathrm{K}$ adalah Konstanta, $\mathrm{T}$ adalah Time of exposure (waktu pengujian), A adalah luas permukaan yang direndam $\left(\mathrm{cm}^{2}\right)$, W adalah kehilangan berat (gram), dan D adalah density $\left(\mathrm{gr} / \mathrm{cm}^{3}\right)$.

Setelah laju korosi didapat selanjutnya menentukan efisiensi dari penggunaan inhibitor tersebut. Penghitungan efisiensi didapatkan melalui prosentase penurunan laju korosi dengan adanya penambahan dibandingkan dengan laju korosi yang tanpa ditambahkan inhibitor. Penghitungan ini dapat dijabarkan sebagai berikut:

$$
\text { Efisiensi inhibisi }=100 \frac{\text { CrUnhibited }- \text { Cr Inhibited }}{\text { CrUnhibited }}
$$

di mana Cr Unhibited adalah laju korosi tanpa inhibitor (mpy) dan $\mathrm{Cr}$ Inhibited adalah laju korosi dengan inhibitor (mpy).

\section{Hasil dan Pembahasan}

\subsection{Perubahan visual beton dan baja tulangan}

Setelah dilakukan pengujian korosi terlihan perubahan bentuk fisik beton yang mengalami perubahan akibat adanya korosi, hal ini di tandai dengan munculnya cairan bening pada permukaan beton kemudian berubah menjadi kuning kecokelatan dan berwarna hitam. Selain perubahan yang terjadi pada fisik beton, baja tulangan beton juga mengalami korosi pada permukaannya. Perubahan permukaan beton dan baja seperti ditunjukkan pada Gambar 4 .
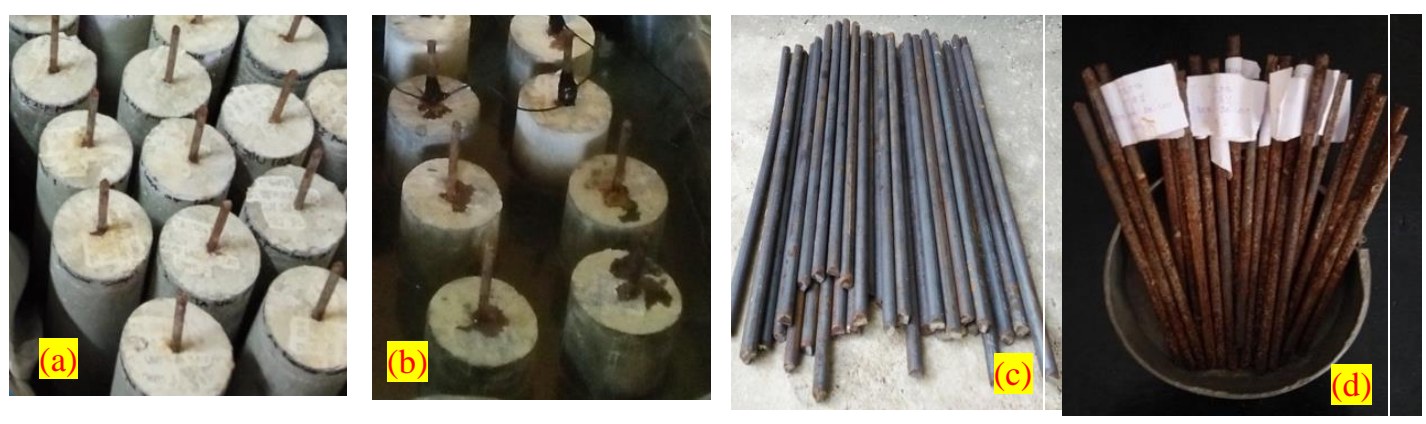

Gambar 4 Perubahan Pada Permukaan Beton (a. Sebelum Pengujian, b. Setelah pengujian) korosi Baja Tulangan (c. Sebelum Pengujian, d. Setelah pengujian)

Penggunaan Ekstrak Tembakau Sebagai Inhibitro Pada Beton Bertulang Menggunakan Pasir Laut Dan Air Laut - Mufti Amir Sultan, Muh. Yunus Hi. Abbas, Abdul Gaus, Khusna Arif Rakhman, Nurtalia Barmawi 


\subsection{Analisa laju korosi}

Laju korosi tulangan yang ditanam dalam benda uji beton dengan menggunakan air laut dan air tawar sebagai bahan pencampur, benda uji beton bertulang menggunakan ekstrak tembakau dengan variasi $0 \%, 4 \%$ dan $8 \%$ terhadap berat semen. Laju korosi dapat dilihat pada Gambar 5, bahwa dengan penambahan konsentrasi ekstrak tembakau (inhibitor) maka laju korosi semakin menurun pada kedua jenis benda uji dengan menggunakan air tawar dan air laut sebagai bahan pencampur beton.

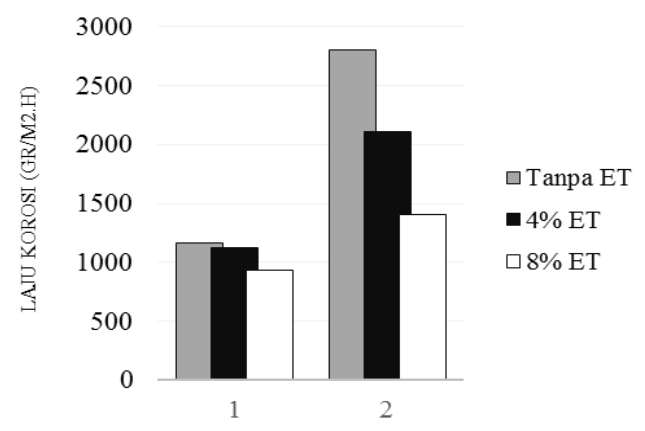

Gambar 5 Diagram Hubungan Laju Korosi Konsentrasi Inhibitor

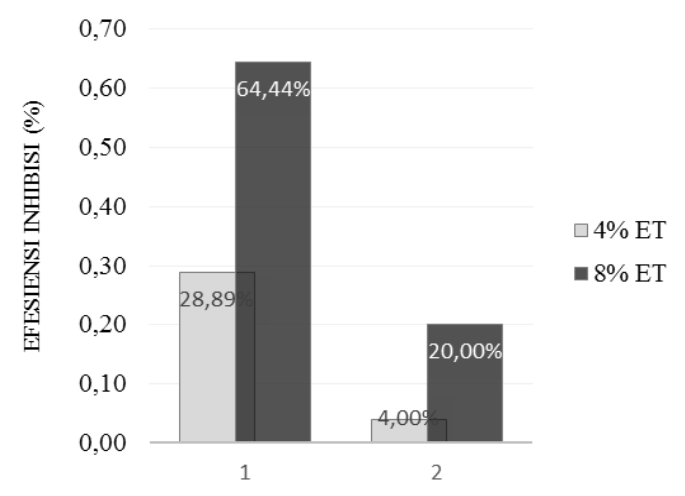

Gambar 6 Diagram Hubungan Efesiensi Inhibitor Terhadap Laju Korosi

Berdasarkan data pada Gambar 6 dapat disimpulkan bahwa penambahan inhibitor ekstrak tembakau dapat menurunkan rapat arus anodik dan katodik yang mengakibatkan laju korosi, semakin tinggi konsentrasi inhibitor yang diberikan maka semakin tinggi pula efesiensi inhibitor tersebut. Rata-rata variasi campuran beton memiliki efesiensi inhibitor yang baik yakni 50\% pada setiap konsentrasi inhibitor $8 \%$ ekstrak tembakau. Secara umum, hasil penelitian menunjukkan bahwa peningkatan konsentrasi inhibitor ekstrak tembakau dapat menurunkan arus korosi baja tulangan yang menyebabkan efesiensi semakin tinggi.

Penambahan ekstrak tembakau mampu meningkatkan efesiensi untuk menekan laju korosi, semakin tinggi konsentrasi ekstrak tembakau (inhibitor) yang diberikan maka semakin tinggi pula efesiensi dari inhibitor tersebut. Hal ini dibuktikan dengan penambahan inhibitor $8 \%$ mampu menekan laju korosi untuk semua variasi campuran beton baik dengan menggunakan air laut dan air tawar sebagai bahan pencampur, efesiensi inhibisi masing-masing 64,44\% dan $20 \%$. 


\subsection{Struktur morfologi korosivitas permukaan beton dan baja}

Proses korisivitas pada permukaan beton dan baja tulangan dilakukan dengan menggunakan alat Scanning Electron Microscopy (SEM). Analisis SEM bertujuan untuk mengetahui struktur morfologi permukaan beton dan baja tulangan pada proses korosi. Hasil analisis menggunakan alat SEM diperlihatkan dalam gambar mikroskopik permukaan material beton dan baja tulangan pada range 500X hingga 30.000X perbesaran, luas area pengamatan permukaan antara 1-2 mikrometer. Hasil analisis SEM pada beton seperti pada Gambar 7.

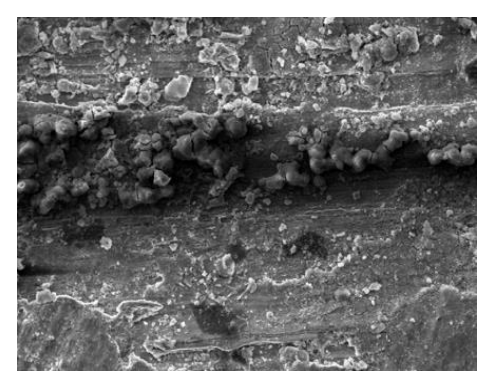

a)Tanpa Ekstrak Tembakau

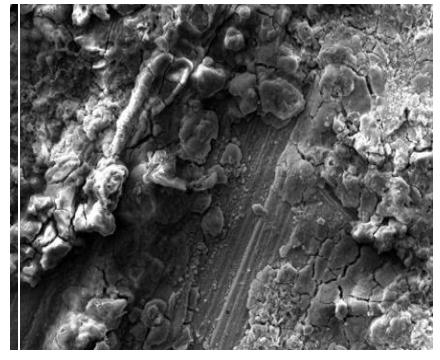

b) Ekstrak Tembakau 4\%

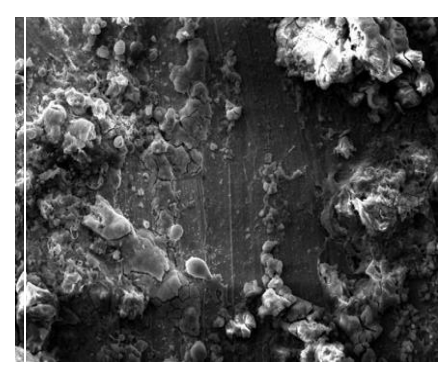

c) Ekstrak Tembakau $8 \%$

Gambar 7 Struktur morfologi beton dengan SEM perbesaran 1000X

Berdasarkan hasil analisis SEM menunjukkan bahwa, tampilan struktur morfologi permukaan beton, terlihat permukaan beton yang tidak rata pada beberapa sampel beton baik tanpa maupun yang menggunakan inhibitor. Kondisi tersebut bisa diakibatkan karena memang kurang padat dan rapatnya permukaan beton, atau bisa juga merupakan proses pengendapan matriks pereaksi oksidasi (agen korosi) yang menempel pada permukaan beton uji.

Hasil analisis SEM pada baja seperti pada Gambar 8. Berdasarkan hasil analisis SEM menunjukkan bahwa, permukaan baja pada beberapa kondisi baik tanpa maupun dengan penambahan inhibitor terjadi kerusakan akibat proses korosi. Pada dasarnya aktivitas korosi yang merupakan proses oksidasi besi (ferum) bahan dasar baja hanya terjadi pada spesi logam tertentu, sehingga aktivitas ini tidak terjadi pada material beton yang lebih banyak berbahan dasar silika baik dari pasir maupun semen.

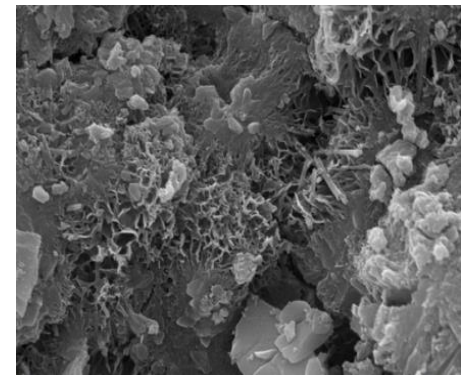

a)Tanpa Ekstrak Tembakau

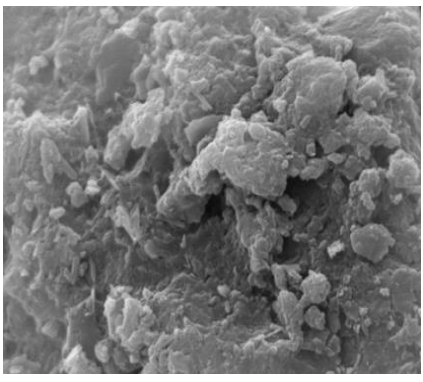

b) Ekstrak Tembakau $4 \%$

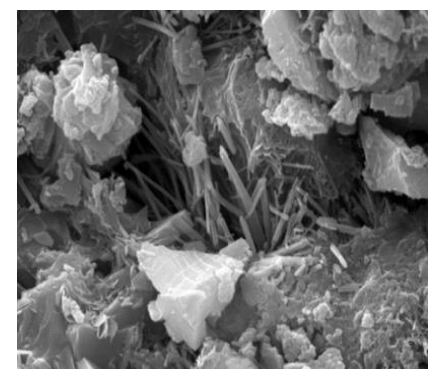

c) Ekstrak Tembakau $8 \%$

Gambar 8 Struktur morfologi korosivitas baja menggunaka SEM perbesaran $20.000 \mathrm{X}$

Penggunaan Ekstrak Tembakau Sebagai Inhibitro Pada Beton Bertulang Menggunakan Pasir Laut Dan Air Laut - Mufti Amir Sultan, Muh. Yunus Hi. Abbas, Abdul Gaus, Khusna Arif Rakhman, Nurtalia Barmawi 
Dari struktur morfologi korosivitas permukaan baja tulangan, dapat dilihat bahwa baja dengan penambahan inhibitor ekstrak tembakau $8 \%$ memiliki struktur permukaan yang lebih rapat dibandingkan yang lain.

\section{Kesimpulan dan Saran}

\subsection{Kesimpulan}

Pengaruh penambahan inhibitor ekstrak tembakau dengan metode weight loss pada konsentrasi $4 \%$ dan $8 \%$ mampu menurunkan rapat arus anodik dan katodik yang mengakibatkan laju korosi pada baja tulangan, semakin tinggi konsentrasi inhibitor yang diberikan maka semakin tinggi pula efesiensi inhibitor tersebut. Hal ini membuktikan bahwa ekstrak tembakau dapat dimanfaatkan sebagai green corrosion inhibitor karena efektif menurunkan laju korosi.

\section{Ucapan terimakasih}

Ucapan terima kasih disampaikan ke LPPM Universitas Khairun yang telah membiayai penelitian ini melalui skema Penelitian Kompetitif Perguruan Tinggi Tahun 2019.

\section{Daftar Kepustakaan}

Abbas, A. S., Fazakas, E. and Torok, T. I., 2018, Corrosion studies of steel rebar samples in neutral sodium chloride, International Journal of Corrosion and Scale Inhibition, 7(1), pp. 38-47. doi: 10.17675/2305-6894-2018-7-1-3.

Ali, F., Saputri, D. and Nugroho, R. F., 2014, Pengaruh Waktu Perendaman Dan Konsentrasi Ektstra Daun Jambu Biji (Psidium guajava, Linn) Sebagai Inhibitor Terhadap Laju Korosi Baja SS 304 Dalam Larutan Garam Dan Asam, Teknik Kimia, 20(1), pp. 28-37.

Andeka, B. P., Suharto, B. and Haji, A. T. S. H., 2015, Efektifitas Limbah Puntung Rokok Sebagai Bahan Inhibitor Korosi Pada Paku Besi Dalam Media Air Tawar, Jurnal Sumberdaya Alam dan Lingkungan, 2(2), pp. 1-6.

Asmara, Y. P. et al., 2018, Application of plants extracts as green corrosion inhibitors for steel in concrete - A review, Indonesian Journal of Science and Technology, 3(2), pp. 158-170. doi: 10.17509/ijost.v3i2.12760.

Bahri, S., 2007, Penghambatan Korosi Baja Beton dalam Larutan Garam dan Asam dengan Menggunakan Campuran Senyawa Butilamina dan Oktilamina, Gradien, 3(1), pp. 231-236.

Haryono, G., Sugiarto, B. and Farid, H., 2010, Ekstrak Bahan Alam sebagai Inhibitor Korosi, in Seminar Nasional Teknik Kimia "Kejuangan" Pengembangan Teknologi Kimia untuk Pengolahan Sumber Daya Alam Indonesia Yogyakarta, pp. 1-6.

Istiqlaliyah, H. and Candrama, P., 2018, Pemanfaatan Limbah Puntung Rokok, Daun Tembakau, dan Kopi Sebagai Inhibitor Besi', Jurnal Mesin Nusantara, 1(1), pp. 1-9. 
Khan, G. et al., 2015, Application of Natural Product Extracts as Green Corrosion Inhibitors for Metals and Alloys in Acid Pickling Processes, International Journal of Electrochemical Science, 10(1), pp. 6120-6134.

Lisha, C., Rajalingam, M. and George, S., 2017, Corrosion Resistance Of Reinforced Concrete With Green Corrosion Inhibitors, International Journal of Engineering Science Invention Research \& Development, 3(11), pp. 687691.

Ludiana, Y. and Handani, S., 2012, Pengaruh Konsentrasi Inhibitor Ekstrak Daun Teh (Camelia sinensis) Terhadap Laju Korosi Baja KArbon Schedule 40 Grade B ERW', Jurnal Fisika Unand, 1(1), pp. 12-18.

Murti, E., Handani, S. and Yetri, Y., 2016, Pengendalian Laju Korosi Pada Baja API 5L Grade B N Menggunakan Ekstrak Daun Gambir (Uncaria Gambir Roxb), Jurnal Fisika Unand, 5(2), pp. 172-178.

Sari, D., Handani, S. and Yetri, Y., 2013, Pengendalian Laju Korosi Baja St-37 Dalam Medium Asam Klorida Dan Natrium Klorida Menggunakan Inhibitor Ekstrak Daun Teh (Camelia Sinensis), Jurnal Fisika Unand, 2(3), pp. 204-211.

Turnip, L. B., Handani, S. and Mulyadi, S., 2015, Pengaruh Penambahan Inhibitor Ekstrak Kulit Manggis Terhadap Penurunan Laju Korosi Baja ST-37, Jurnal Fisika Unand, 4(2), pp. 144-149.

Usman, S. H., Sultan, M. A. and Abbas, M. Y. H., 2019, Penggunaan Abu Sekam Padi Sebagai Inhibitor Alami Pada Tulangan Beton Bertulang, SIPILsains, 9(18), pp. 47-58.

Yatiman, P., 2009, Penggunaan Inhibitor Organik Logam (Application of Organic Inhibitors for Corrosion Control of Metals and Alloys), Seminar Nasional Penelitian, Pendidikan dan Penerapan MIPA, Fakultas MIPA, Universitas Negeri Yogyakarta, p. Hal. 134-142.

Yetri, Y., Sari, D. M. and Handani, S., 2016, Effisiensi Inhibisi Inhibitor Ekstrak Daun Teh (Camelia sinensis) Terhadap Baja St-37 dalam Medium Asam dan Garam, Jurnal Katalisator, 1(1), pp. 1-10. doi: 10.22216/jk.v1i1.1407.

Yufita, E. and Fitriana, D., 2018, Pengendalian Laju Korosi Pada Baja Plat Hitam a36 Dalam Medium Korosif Menggunakan Inhibitor Ekstrak Daun Salam Control of Corrosion Rate on a36 Black Plate Steel in Corrosive Medium Using Salam Leaf, Journal of Aceh Physics Society, 7(2), pp. 67-71. 